\title{
Fibrous myopathy as a complication of repeated intramuscular injections for chronic headache
}

\author{
R Burnham MD FRCPC ${ }^{1}$, S McNeil MD FRCPC ${ }^{2}, \mathrm{C} \mathrm{Hegedus} \mathrm{MD} \mathrm{FRCPC}^{3}$, DS Gray MD PhD FRCPC ${ }^{1}$
}

\begin{abstract}
R Burnham, S McNeil, C Hegedus, DS Gray. Fibrous myopathy as a complication of repeated intramuscular injections for chronic headache. Pain Res Manage 2006;11(4):249-252.

Two cases of fibrous myopathy associated with repeated, long-term intramuscular injections for treatment of chronic temporomandibular joint pain and chronic headache, respectively, are described. Both patients developed severe, function-limiting contractures in upper and lower extremity muscles used as injection sites. In one of the cases, the contractures were painful. Electrophysiological testing, magnetic resonance imaging and muscle biopsy results were all consistent with myopathy and replacement of skeletal muscle with noncontractile fibrous tissue. These cases are presented to increase awareness of fibrous myopathy and to promote surveillance for this serious potential complication of long-term intramuscular injections in chronic headache and other pain patients.
\end{abstract}

Key Words: Analgesic injection; Contracture; Fibrous myopathy; Injection complication

Cocal myopathy resulting in the fibrous replacement of mus-

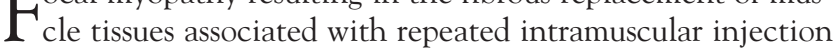
has been sporadically described in previous case reports in children and adults. This fibrous myopathy has frequently been associated with the chronic intramuscular administration of narcotic analgesics such as pentazocine (1-9), butorphanol (10), propoxyphene (11), heroin (12), piritramide (13), methadone (14) and meperidine (15-18). We present two cases of fibrous myopathy and attendant joint contracture associated with long-term intramuscular analgesic and other drug use for chronic headache. In one of the patients, pain from the fibrous myopathy eventually exceeded that from the headaches. These cases not only illustrate fibrous myopathy as a complication of chronic intramuscular injection, but also show the devastating functional impairment and disability that may arise from extensive muscle fibrosis and contracture development.

\section{CASE PRESENTATIONS}

\section{Case 1}

A 30-year-old woman used intramuscular injections of meperidine every $2 \mathrm{~h}$ to $3 \mathrm{~h}$ over a seven-year period in an attempt to control chronic temporomandibular joint pain that developed following a motor vehicle collision. A variety of other pain control modalities, including occlusal splinting, stellate ganglion blocks, temporomandibular joint injections, physiotherapy, chiropractic treatments, naturopathy, craniosacral therapy, narcotic and non-narcotic analgesics, anticonvulsant medication, trigger point injections, biofeedback, massage therapy

\section{La myopathie fibreuse : complication de l'ad- ministration répétée d'injections intramuscu- laires pour le soulagement de céphalées chroniques}

\begin{abstract}
Voici deux cas de myopathie fibreuse associée à l'administration répétée d'injections intramusculaires pour le soulagement à long terme d'arthralgie temporo-mandibulaire chronique et de céphalées chroniques, respectivement. De fortes contractures invalidantes sont apparues dans les muscles des membres supérieurs et inférieurs ayant servi aux injections. Dans un des cas, les contractures étaient douloureuses. L'exploration électrophysiologique, l'imagerie par résonance magnétique et la biopsie musculaire ont toutes confirmé la présence de myopathie et le remplacement des muscles squelettiques par du tissu fibreux, non contractile. La présentation de ces deux cas vise à sensibiliser les médecins à la myopathie fibreuse et à surveiller l'apparition possible de cette complication sérieuse chez les patients souffrant de céphalées chroniques et d'autres types de douleur par suite de l'administration répétée d'injections intramusculaires.
\end{abstract}

and biofeedback therapy, had been tried without success. A specialty pain clinic eventually suggested self-administered intramuscular narcotic analgesics. She obtained some pain relief with intramuscular injections of meperidine at a typical dose of $50 \mathrm{mg}$ approximately every $2 \mathrm{~h}$ to $3 \mathrm{~h}$. Injections initially targeted her thighs and hip girdle, but she switched to the shoulder girdle and upper arm after approximately three years when she noticed reduced analgesic effect of the injected narcotic and the development of lower extremity muscle firmness and bilateral contractures of the hips and knees. Muscle firmness and contracture began to develop in the upper extremities approximately one year before presentation. In addition to the contractures and muscle firmness, she developed wrist and finger extension weakness that was clinically consistent with radial nerve injury.

On examination, her gait was abnormal, with knees locked into 20 degrees of hyperextension. There was limited active hip flexion, and forward progress was made by hip-hiking, circumduction of the swing-phase leg and pelvic rotation. Active and passive range of motion was restricted at the shoulders, with limitations in abduction, forward flexion and external rotation. Shoulder girdle power was graded as antigravity without resistance. Elbow flexion and extension were restricted to a total range of approximately 30 degrees. Elbow flexion power varied from allowing flexion without gravity to flexion against gravity without resistance. Passive range of movement in the wrists and fingers was normal, although there was right-sided weakness of wrist and finger extension. Hip range was limited

${ }^{1}$ University of Alberta, Division of Physical Medicine and Rehabilitation, Edmonton; ${ }^{2}$ Foothills Medical Centre, Division of Clinical Neurosciences, Calgary; ${ }^{3}$ Red Deer Regional Hospital, David Thompson Health Region, Red Deer, Alberta

Correspondence and reprints: Dr DS Gray, Division of Physical Medicine and Rehabilitation, University of Alberta, clo 1226 Glenrose

Rehabilitation Hospital, 10230 - 111 Avenue, Edmonton, Alberta T5G 0B7. E-mail dsgray@dthr.ab.ca 


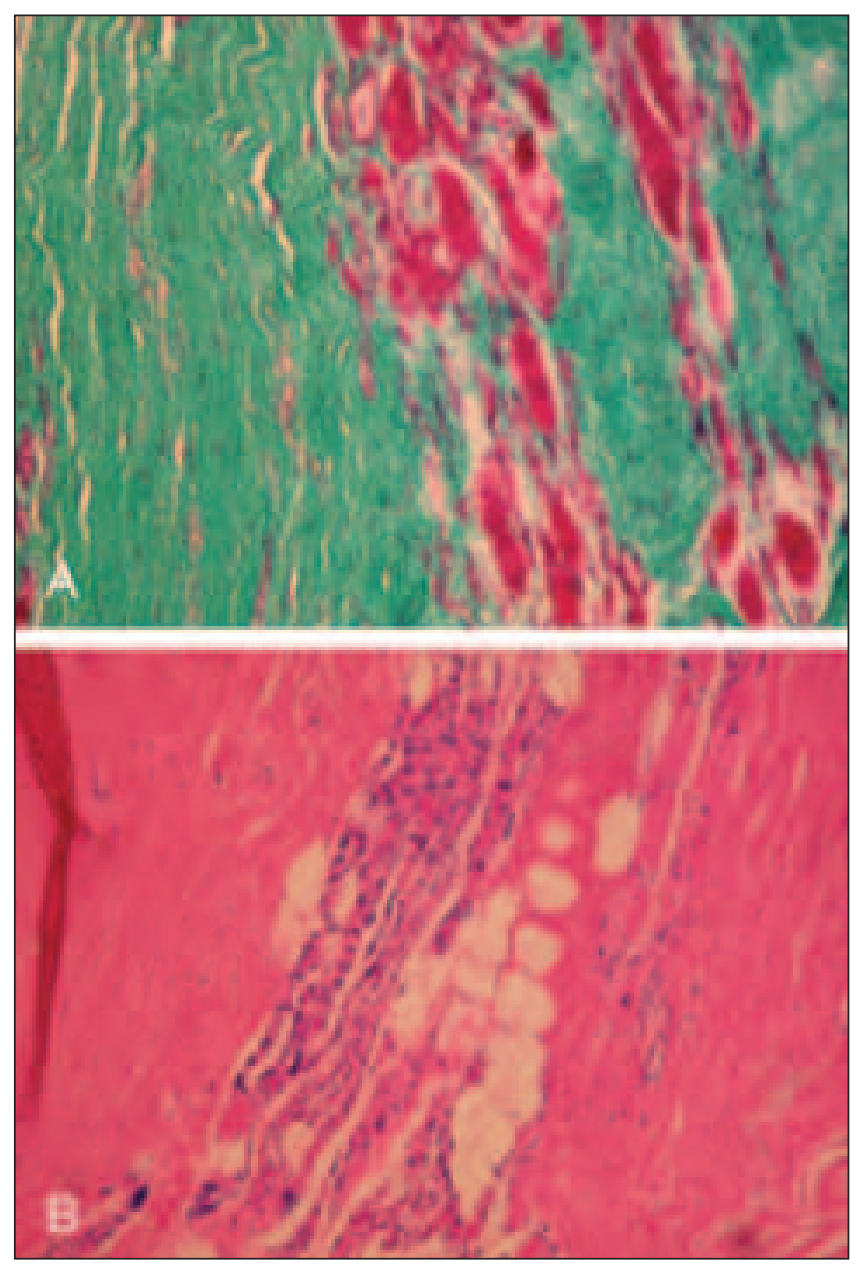

Figure 1) A Modified Gomori trichrome staining showed densely sclerotic tissue with intersecting, mildly hypercellular, bundles of densely collagenous fibrous tissue entrapping vascular pedicles in case 1. B Hematoxylin and eosin preparation showing extensive replacement of muscle tissue with collagen in case 2

to 25 degrees of abduction bilaterally, 15 degrees of flexion bilaterally, minimal internal rotation and approximately 60 degrees of external rotation. There was only 15 degrees of available range at the knees, and knee flexion was functionally absent, resulting in fixation of the knees in extension. Range of motion and motor power at the ankles was normal. There was no sensory compromise, and tendon reflexes were somewhat reduced in amplitude. The muscles of the arm and shoulder girdles, as well as those of the proximal leg and pelvic girdle, were firm but nontender to palpation. Functionally, she was dependent on assistance for some activities of daily living and could not sit or drive because of the contractures. Her gait was painful, slow and inefficient. She used a number of adaptive devices such as long-handled eating utensils, a bath stick, a single-point cane and adapted toilet facilities. She was unable to work.

Electrodiagnostic studies of the affected muscles showed decreased needle electromyographic insertional activity with a dense feel to the tissue on insertion, a reduced number of motor units with mixed myopathic and neuropathic features, and electrophysiological evidence of distal right ulnar and median dysfunction. No active motor units could be identified in the right triceps, biceps or deltoid muscles. These results were thought to be consistent with fibrous replacement of muscle tissue and probable compressive peripheral neuropathy, similar to previous reports $(1,9,18)$.

Initial muscle biopsy from the left quadriceps muscle showed poorly cellular, collagenized, elastotic, fibrous tissue. There were a few small islands of atrophic skeletal muscle present. There were no significant areas of inflammation or inclusion. The pathological diagnosis was one of extensive scarring. Further pathological assessment with hematoxylin and eosin and modified Gomori trichrome staining showed densely sclerotic tissue with intersecting, mildly hypercellular bundles of densely collagenous fibrous tissue entrapping vascular pedicles. No muscle fibres were visualized. The tissue biopsy was consistent with fibrous myopathy. Representative histology is shown in Figure 1A.

In view of progression of the contractures, she was treated with prednisone in a tapering course, with some minor improvement in the passive range in the wrists and fingers. Although there was perhaps some 'softening' of the muscle and decrease in firmness of the contractures following corticosteroid treatment, there was no overall change in her degree of disability. Treatment with penicillamine as described by Weber et al (12) was considered but not implemented after discussion of possible risks and benefits with the patient.

\section{Case 2}

A 42-year-old woman initially presented with refractory migraine headache. Other than a history of treated hypothyroidism, she was generally healthy. Before starting the intramuscular injection regimen as suggested by a tertiary headache clinic, she had been unsuccessfully treated with a variety of oral medications, including narcotic and non-narcotic analgesics, antispasticity agents, tricyclic antidepressants and benzodiazepines. The self-administered intramuscular injections consisted of meperidine, diphenhydrinate, dihydroergotamine and sumatriptan succinate into the hip girdle and quadriceps muscles bilaterally over an eight-year period. The injection frequency was approximately four to five injections per week. Five years after initiating these injections, she developed progressive pain and stiffness of the lower extremities associated with subjective painful 'snapping' at the lateral aspects of the hips, with pain and stiffness progressing more proximally to the buttock muscles. Clinically, it was thought that the painful lateral hip snapping was related to fibrous, taut iliotibial bands crossing over the greater trochanter during hip flexion and extension. This muscle pain was not controllable with an oral narcotic analgesic, and became more severe and disabling than the presenting headaches. Functionally, she was unable to work, had disturbed sleep, could not climb stairs and could not do heavy cleaning. Her gait was slow, painful and restricted to short distances. The hip girdle and leg pain were poorly controlled despite additional oral medications (including nonsteroidal anti-inflammatory drugs, prednisone and narcotic analgesics), as well as the use of other modalities such as physiotherapy, acupunctures and steroid injections.

Examination showed 20 degrees of hip abduction contracture on the left and 10 degrees of contracture on the right. Passive hip flexion range of motion was limited to 80 degrees on the left and 110 degrees on the right. There was marked firmness and a degree of tenderness to palpation over the anterior and lateral thighs, as well as the gluteal regions bilaterally. 
Much of the range appeared to be limited by discomfort. Examination under anesthesia was therefore undertaken and showed improvement in passive hip flexion ranges to approximately 135 degrees bilaterally. Passive hip adduction range was almost nonexistent, and there was minimal external hip rotation range bilaterally. Passive abduction and internal rotation showed essentially normal ranges.

Serum chemistry tests, including erythrocyte sedimentation rate, antinuclear antibody, rheumatoid factor, creatine kinase and serum protein electrophoresis testing were all within normal limits. Magnetic resonance imaging of the hip girdle showed increased fibrosis at the lateral pelvis in the region of the gluteus medius muscles bilaterally.

Electrodiagnostic studies showed normal motor and sensory nerve conductions, as well as normal H-reflex studies. Needle electromyographical examination of the gluteus maximus muscle showed decreased insertional activity, no spontaneous motor activity or motor unit recruitment. There was a hard, fibrous texture noted on needle insertion.

Muscle biopsy of the left vastus lateralis muscle showed diffuse sheets of dense, sparsely cellular fibrocollagenous tissue. There was no muscle tissue noted in the specimens. Representative biopsy findings are shown in Figure 1B.

The intramuscular injections were discontinued. Surgical lengthening of her iliotibial bands was considered but not undertaken when an examination under anesthesia demonstrated that a significant part of her soft tissue movement limitation was pain related. She eventually obtained dramatic relief of her contracture pain with a temporary indwelling epidural catheter infusion of a local anesthetic. This was discontinued after a few days due to infection of the catheter line. Treatment with long-acting oral narcotics was resumed, and she was referred for an implantable stimulator trial.

\section{DISCUSSION}

These case presentations are remarkable for the degree of replacement of normal muscle tissue and proliferation of fibrous connective tissue associated with long-term injection of analgesic medication. Both patients developed severe impairment of normal joint function and consequent severe disability in addition to the suffering already associated with their chronic headache. The second case is somewhat unusual given the muscle tenderness and pain accompanying the development of the myopathy, a feature not generally associated with fibrous myopathy in previous reports. We consider the additional pain, loss of muscle and joint function, and disability to be iatrogenic in nature, caused by the chronic intramuscular use of meperidine and other medications.

In adults, fibrous myopathy seems to have been most often described in association with the repeated intramuscular injection of narcotic agents. A number of narcotic agents have been implicated, including meperidine (as in the cases presented here) (15-18), pentazocine (1-8), butorphanol (10), propoxyphene (11), heroin (12), piritramide (13) or methadone (14). It is unclear, given the small number of adult cases reported in the literature, whether fibrous myopathy is simply the result of frequent, repeated, needle-related muscle trauma and repair or if there is some other risk associated with an additional myotoxic or vasotoxic effect of the narcotic agents outlined above $(8,12,19,20)$. A literature search of CINAHL, EMBASE and MEDLINE found only one case of adult fibrous myopathy not associated with narcotics (21) - although there does seem to be a clearer association with both repeated intramuscular trauma and antibiotic use in children $(22-24)$. The fact that both cases presented here were women is of unknown significance, although fibrous myopathy has been reported in both males and females.

The association of fibrous myopathy with narcotic use and repeated injection highlights the fact that this condition is iatrogenic and a consequence of the method chosen for pain control. Despite sporadic case reports of fibrous myopathy in adults and children dating back to the 1970 s $(3,15,23)$, our cases highlight that this complication of chronic intramuscular injection still exists in the new millennium, and may therefore reflect a lack of clinical experience and awareness of this relatively rarely reported condition. The natural history of fibrous myopathy is largely unclear, and it is not known whether there is a threshold absolute number or particular frequency of injections or muscle trauma that results in fibrous replacement of muscle tissue. It is possible that focal myopathy, fibrosis and contracture associated with repeated narcotic injection may be reversible in early stages of the myopathy, before muscle tissue is replaced by noncontractile fibrous tissue and permanent disability results (12). Treatment may consist of stopping injections and considering the addition of corticosteroids and/or penicillamine as suggested by Weber et al (12). We note, however, that both cases presented here were treated with oral corticosteroids during the course of their myopathies with no dramatic effects on reversing or slowing progression of the fibrous contractures. If chronic intramuscular injection cannot be avoided, we recommend close serial monitoring of the muscles being injected. Hardening of muscle tissue, loss of muscle strength or range of motion, muscle tenderness or pain, or increasing functional disability should prompt review of the injections and a search for alternative pain control interventions.

\section{REFERENCES}

1. Sinsawaiwong S, Phanthumchinda K. Pentazocine-induced fibrous myopathy and localized neuropathy. J Med Assoc Thai 1998;81:717-21.

2. Adams EM, Horowitz HW, Sundstrom WR. Fibrous myopathy in association with pentazocine. Arch Intern Med 1983;143:2203-4.

3. de Lateur BJ, Halliday WR. Pentazocine fibrous myopathy: Report of two cases and literature review. Arch Phys Med Rehabil 1978;59:394-7.

4. Jain A, Bhattacharya SN, Singal A, Baruah MC, Bhatia A. Pentazocine induced widespread cutaneous and myo-fibrosis. J Dermatol 1999;26:368-70.

5. Rousseau JJ, Reznick M, LeJeune GN, Franck G. Sciatic nerve entrapment by pentazocine-induced muscle fibrosis: A case report. Arch Neurol 1979;36:723-4.

6. Levin BE, Engel WK. Iatrogenic muscle fibrosis. Arm levitation as an initial sign. JAMA 1975;234:621-4.

7. Oh SJ, Rollins JL, Lewis I. Pentazocine-induced fibrous myopathy. JAMA 1975;231:271-3.

8. Kim HA, Song YW. Polymyositis developing after prolonged injections of pentazocine. J Rheumatol 1996;23:1644-6.

9. Kim LYS. Compression neuropathy of the radial nerve due to pentazocine-induced fibrous myopathy. Arch Phys Med Rehabil 1987;68:49-50.

10. Wagner JM, Cohen S. Fibrous myopathy from butorphanol injections. J Rheumatol 1991;18:1934-5.

11. Restrepo JF, Guzman R, Pena MA, et al. Fibrous myopathy induced by propoxyphene injections. J Rheumatol 1993;20:596-7.

12. Weber M, Diener HC, Voit T, Neuen-Jacob E. Focal myopathy induced by chronic heroin injection is reversible. Muscle Nerve 2000;23:274-7. 


\section{Burnham et al}

13. Van den Bergh PYK, Guettat L, Vande Berg BC, Martin J. Focal myopathy associated with chronic intramuscular injection of piritramide. Muscle Nerve 1997;20:1598-600.

14. Carpintero P, Kindelan J, Lluch M, Mesa M. Methadone-induced fibrous and calcified myopathy - A report of 2 cases. Acta Orthop Scand 1996;67:404-6.

15. Johnson KR, Hsueh WA, Glusman SM, Arnett FC. Fibrous myopathy. A rheumatic complication of drug abuse. Arthritis Rheum 1976;19:923-6.

16. Mastaglia FL, Gardner-Medwin D, Hudgson P. Muscle fibrosis and contractures in a pethidine addict. Br Med J 1971;4:532-23.

17. Yamanaka M, Parsa FD. Compression neuropathy from muscle fibrosis induced by repeated meperidine injections. Plast Reconstr Surg 1985;75:582-3

18. Midroni G, Moulton R. Radial nerve entrapment neuropathy due to chronic injection-induced triceps fibrosis. Muscle Nerve 2001;24:134-7.
19. Mastaglia FL. Adverse effects of drugs on muscle. Drugs 1982;24:304-21.

20. von Kemp K, Herregodts P, Duynslaeger L, Deleu D, Bruyland M, Cham B. Muscular fibrosis due to chronic intramuscular administration of narcotic analgesics. Acta Clin Belg 1989;44:383-7.

21. Brumback RA, Empting L, Susag ME, Staton RD. Muscle fibrosis associated with intramuscular chlorpromazine administration. A preliminary report. J Pharm Pharmacol 1982;34:526-8

22. Babhulkar SS. Triceps contracture caused by injections. A report of 11 cases. J Bone Joint Surg Br 1985;67:94-6.

23. Norman MG, Temple AR, Murphy JV. Infantile quadriceps femoris contracture resulting from intramuscular injections. N Engl J Med 1970;282:964-6.

24. Stark WA. Quadriceps contracture in children. Am J Dis Child 1970;120:349. 


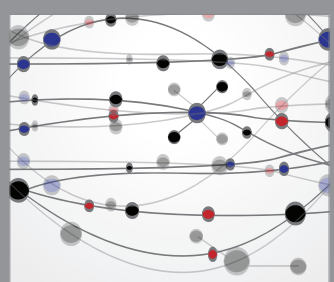

The Scientific World Journal
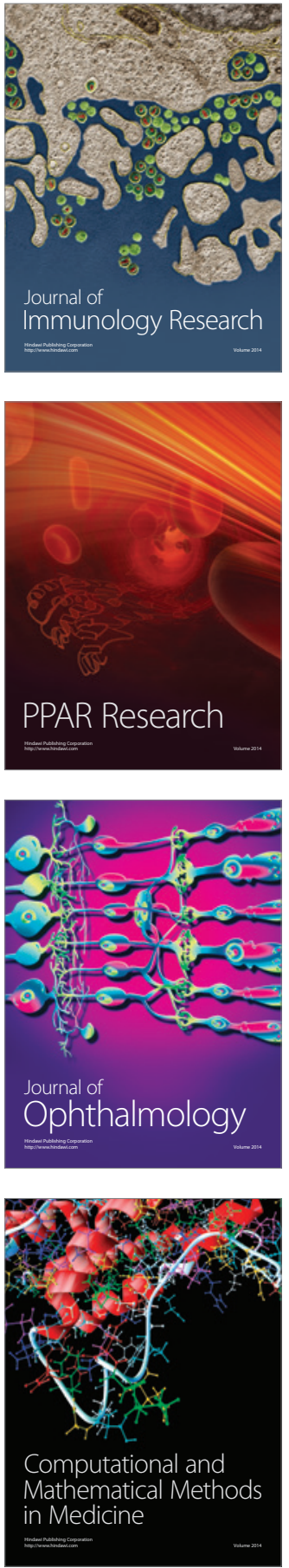

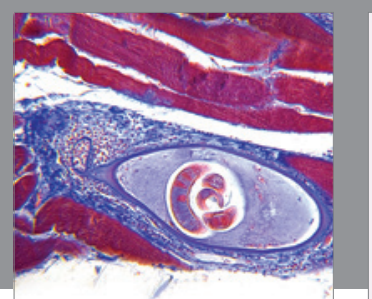

Gastroenterology Research and Practice

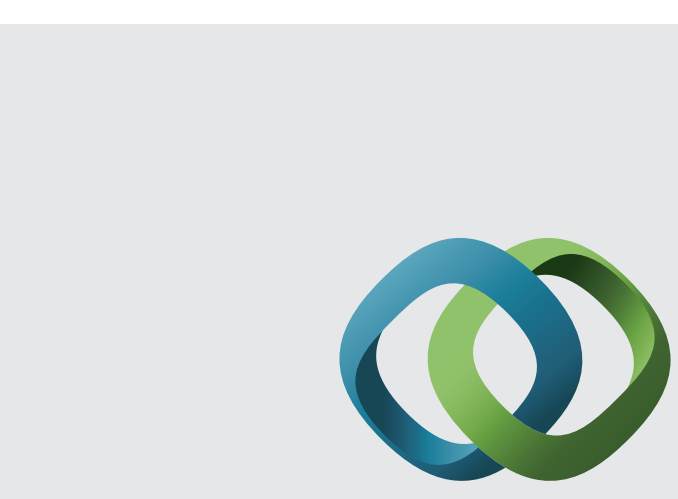

\section{Hindawi}

Submit your manuscripts at

http://www.hindawi.com
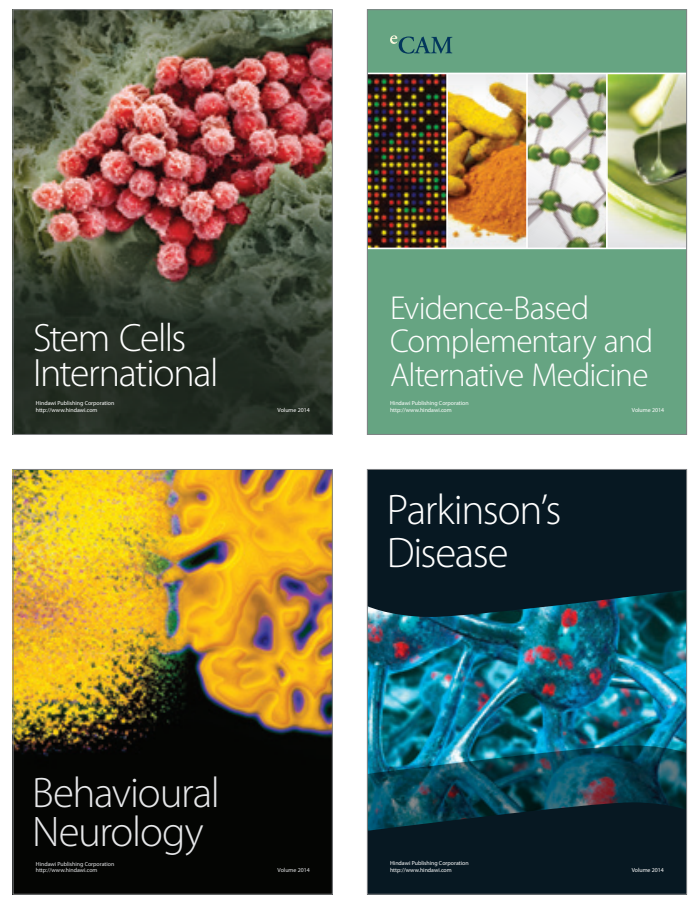
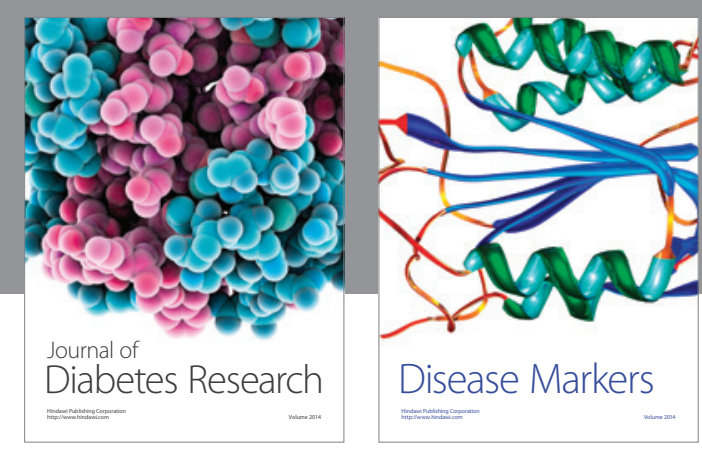

Disease Markers
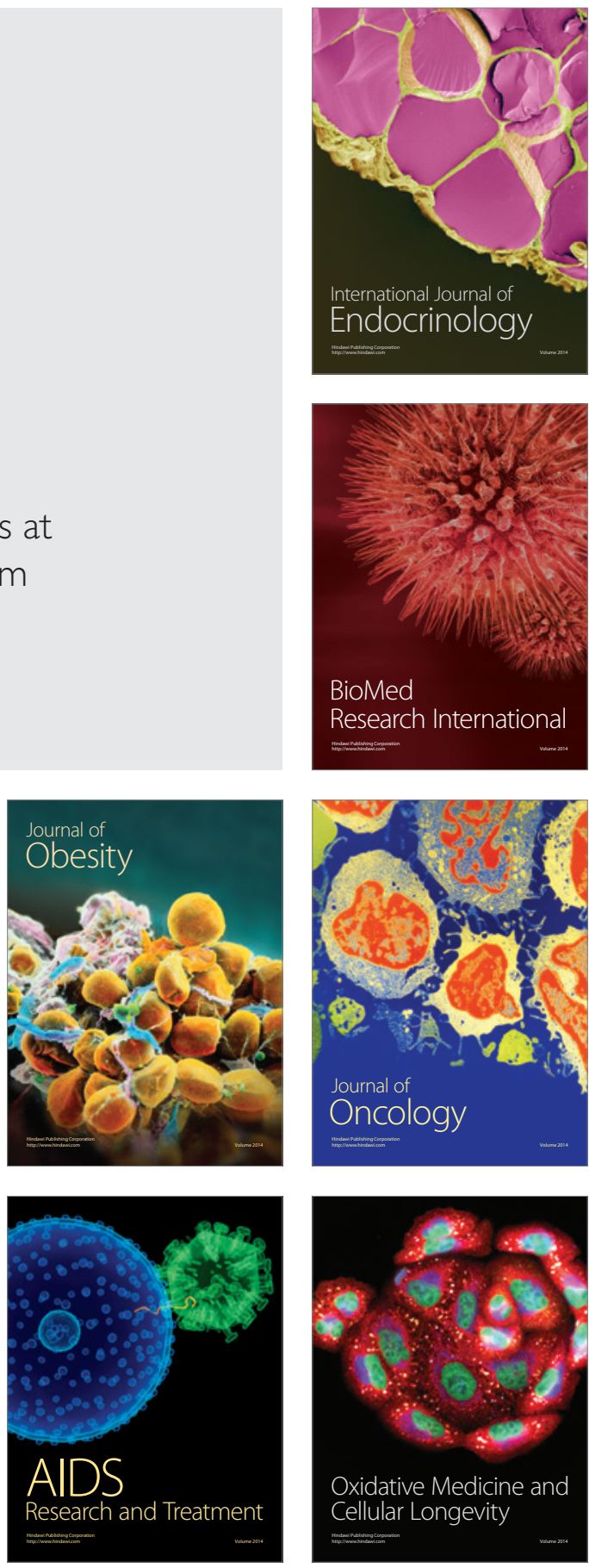